\title{
Post-farmgate food value chains make up most of consumer food expenditures globally
}

\author{
Jing Yi ${ }^{1}$, Eva-Marie Meemken ${ }^{\circledR 2}$, Veronica Mazariegos-Anastassiou1, Jiali Liu $\mathbb{1}^{3}$, Ejin Kim', \\ Miguel I. Gómez ${ }^{10}$, Patrick Canning ${ }^{4}$ and Christopher B. Barrett $\mathbb{1}^{1,3 凶}$
}

\begin{abstract}
Progress towards many United Nations Sustainable Development Goals depends on interventions in food value chains, yet data and methods have thus far limited the production of cross-nationally comparable estimates of food value chains' magnitudes. Here we develop a standardized method and data series to estimate the distribution of consumer food expenditures between value-added activities on farms and in the post-farmgate value chain. Using data from 61 countries over 2005-2015, representing $\mathbf{9 0 \%}$ of the global economy, we show that farmers receive, on average, $27 \%$ of consumer expenditure on foods consumed at home and a far lower percentage of food consumed away from home. That figure consistently falls in the $16-38 \%$ range for middle- and high-income countries and falls significantly as incomes rise. The large and growing post-farmgate food value chain merits greater attention as the world grapples with the economic, environmental and social impacts of food systems.
\end{abstract}

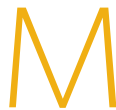

any observers recognize the magnitude of the role played by post-harvest food value chain (FVC) intermediationthe various processing, storage, transport, wholesaling, retailing, food service and other functions that transform farm commodity outputs into the foods that humans consume multiple times every day. High-level, recent studies ${ }^{1}$ highlight how FVCs impact various economic, environmental, health and social outcomes and are central to realizing most of the 17 Sustainable Development Goals (SDGs) adopted by all United Nations member states in 2015, especially SDGs 1 (no poverty), 2 (zero hunger), 3 (good health and well-being), 6 (clean water and sanitation), 7 (clean and affordable energy), 8 (decent work and economic growth), 10 (reduced inequalities), 12 (responsible consumption and production), 13 (climate action), 14 (life below water) and 15 (life on land). In addition, the United Nations Food Systems Summit 2021 explicitly recognizes the importance of adopting a food systems approach inclusive of FVCs when considering policies to address farm, food safety and environmental issues ${ }^{2}$. The COVID-19 pandemic has also revealed how FVC logistical constraints can lead to the painful juxtaposition of farmers dumping unsellable milk and perishable produce at the same time as food shops run out of stock and ration purchases of increasingly expensive perishables such as eggs ${ }^{3,4}$.

Yet as scholars and policymakers deliberate over how best to transform FVCs to achieve the SDGs and build resilience to systemic shocks, attention typically focuses on the two ends of the value chain, namely downstream on final food consumers and upstream on farmers, fishers, herders and other primary producers of agricultural commodity feedstocks. More disaggregated data on FVC operations that occur between farms and consumers are needed to assess changes over time and to identify prospective entry points for interventions that aim to advance SDGs and other goals. But estimates of the magnitude of value chain intermediation remain elusive.

We hypothesize that the post-farmgate FVC gets insufficient attention at least in part due to a dearth of standardized data and methods to systematically generate internationally comparable estimates of its magnitude and drivers. Many studies exist that unpack FVC marketing margins for individual commodities or countries ${ }^{5-7}$. These previous studies convincingly establish the qualitative point that the post-farmgate portion of FVCs is large, growing and vibrant. But case studies necessarily represent a small share of the total food economy of the study countries, are typically not directly comparable across countries, and usually omit the considerable share of food expenditures on manufactured products and prepared foods that combine multiple commodities, rather than merely transform the identity of a single commodity (for example, through milling a cereal into flour). A different method is needed to generate systematic, economy-wide and cross-nationally comparable quantitative estimates.

The value of a systematic, economy-wide FVC data series is evident in the United States, where the US Department of Agriculture's (USDA's) Economic Research Service (ERS) has published the 'food dollar series' annually since 1947 to measure the value of post-farmgate activities ${ }^{8,9}$, as legally mandated by the Agricultural Marketing Act of 1946. The food dollar series has deeply influenced how researchers, policymakers and FVC actors in the United States think of and approach food policies and agri-food business practices. The food dollar data series has been used to examine competitiveness and performance during a period of rapid transformation of FVCs, to inform anti-trust policy and to design policy interventions to protect family farms, among others ${ }^{10,11}$. Canada is the only other country in which a comparable series has been constructed, for the 1997-2010 period $^{9}$.

The ERS food dollar series taps the international System of National Accounts (SNA) and the UN's related system of environmental-economic accounting ${ }^{12}$, which have sparked a long stream of research and policy interventions to promote sustainable economic growth but have not been widely applied to FVCs. The food dollar series has enabled more direct study of the salient FVC features of the US agri-food economy, which are typically obscured in countries' standard SNA, by facilitating the incorporation of comparable FVC data into broader models intended to guide sustainable development and food policy design and evaluation ${ }^{10,13-15}$. Scaling

${ }^{1}$ Charles H. Dyson School of Applied Economics and Management, Cornell University, Ithaca, NY, USA. ${ }^{2}$ Department of Food and Resource Economics, University of Copenhagen, Copenhagen, Denmark. ${ }^{3}$ Department of Economics, Cornell University, Ithaca, NY, USA. ${ }^{4}$ Economic Research Service, United States Department of Agriculture, Seattle, WA, USA.凶e-mail: cbb2@cornell.edu 

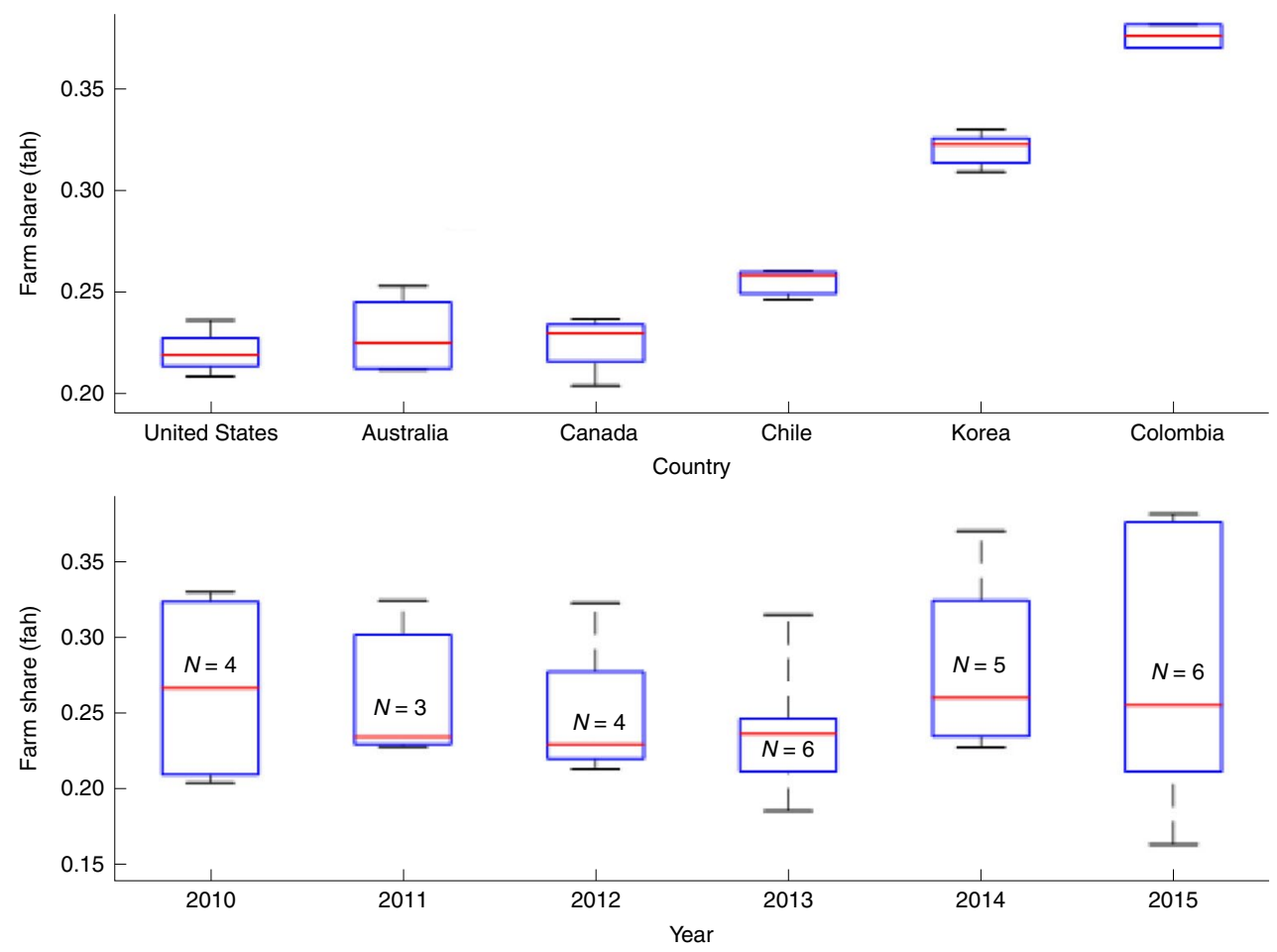

Fig. 1 | Farm share of consumer fah. The top panel shows box and whisker plots of farm shares of consumer food expenditures at home for those countries with multiple fah observations over the period 2005-2015. The bottom panel shows box and whisker plots of farm shares of consumer food expenditures at home for the period 2010-2015. The red line in each box is the median. The bottom and top edges of each box are the 25th and 75th percentiles, respectively. The two horizontal lines outside the boxes indicate the maximum and minimum values. $N$ is the number of country observations available for that year. The cross-country and within-country ranges of the farm share of domestic expenditures on fah has not varied appreciably over the period, remaining consistently in the $20-40 \%$ range. Post-farmgate value addition routinely represents two-thirds or more of the value of consumer food expenditures.

and adapting the ERS method globally enables similar direct studies for the global agri-food economy.

Our main contribution is to introduce the 'global food dollar' method, which adapts and scales the ERS food dollar series method ${ }^{8}$ globally. We apply it to the SNA data reported in the Organisation for Economic Co-operation and Development (OECD) harmonized national input-output and use tables ${ }^{16}$ over a period of 11 years (2005-2015) for 61 middle- and high-income countriesnot just OECD member states-with real gross national income (GNI) per capita ranging from US\$1,969 to US\$85,422 per year (Supplementary Information and Supplementary Table 1). Together, these countries represented about $90 \%$ of global GNI and $70 \%$ of the world's population in $2017^{17}$. In addition to introducing the global food dollar method, we also discuss prospective extensions to this method to examine the environmental and labour footprints of rapidly evolving FVCs. Finally, to validate the usefulness of the global food dollar method, we use multivariate regression analyses to confirm that the share of post-farmgate food value addition correlates positively with key development indicators such as per capita income, a well-known stylized fact but one unconfirmed in standardized, cross-country panel data.

The resulting global food dollar comparative analysis underscores that FVCs worldwide are dominated by post-farmgate actors and are poised to become even more so as incomes grow in the years ahead. This method and initial proof-of-concept data series open up exciting opportunities for standardized, global analysis to unpack the world's FVCs in various economic and environmental dimensions.

\section{Results}

The global food dollar method lets us divide consumer food purchases between farmers' receipts from sales of raw food commodities and agricultural feedstocks-which together comprise farmer input costs and profits-and the value added by food supply chain intermediaries for all post-farmgate activities, netting out inter-industry exchange. We focus on domestic FVCs for the simple reason that roughly three-quarters of all food is consumed in the same country as its raw commodity inputs were grown ${ }^{18}$. Food consumers in their home country represent most farmers' primary market. However, even domestic FVC's are likely to use imported ingredients (such as imported grains milled domestically) and other imported inputs (such as imported fertilizers used on domestic farms). What is excluded in this definition of domestic value chains are imported foods and beverages directly marketed to consumers without undergoing any further processing, such as imported cheeses sold in retail markets or purchased by a restaurant from an importing wholesaler.

The mean (standard deviation) farm share of nominal food expenditures in 2015 was 0.27 (0.09) for food at home (fah), which reflects conventional retail purchases for preparation by the purchaser. Over the 2005-2015 period, the fah farm share consistently fell in the 16-38\% range across all the high- and middle-income countries in our sample (Fig. 1 and Supplementary Table 2). We observe no statistically significant change over the period in the small sample of ten countries for which fah series can be currently constructed. A related, relevant indicator is the farm share in GNI. We calculate this by multiplying the farm share of fah by the food expenditures (fah) share of GNI (that is, adjusting the farm share for the Engel elasticity that relates food expenditure response to income change). For the small set of countries where fah is available, the farm shares of GNI are lowest (highest) in the United States (Colombia) with a mean of $0.9 \%$ (2.3\%) over the period 2010-2015 (Fig. 2). The average annual farm shares of GNI range from 0.9 to $1.6 \%$ in 2011 and 2014, respectively. The often-overlooked magnitude of the FVC 

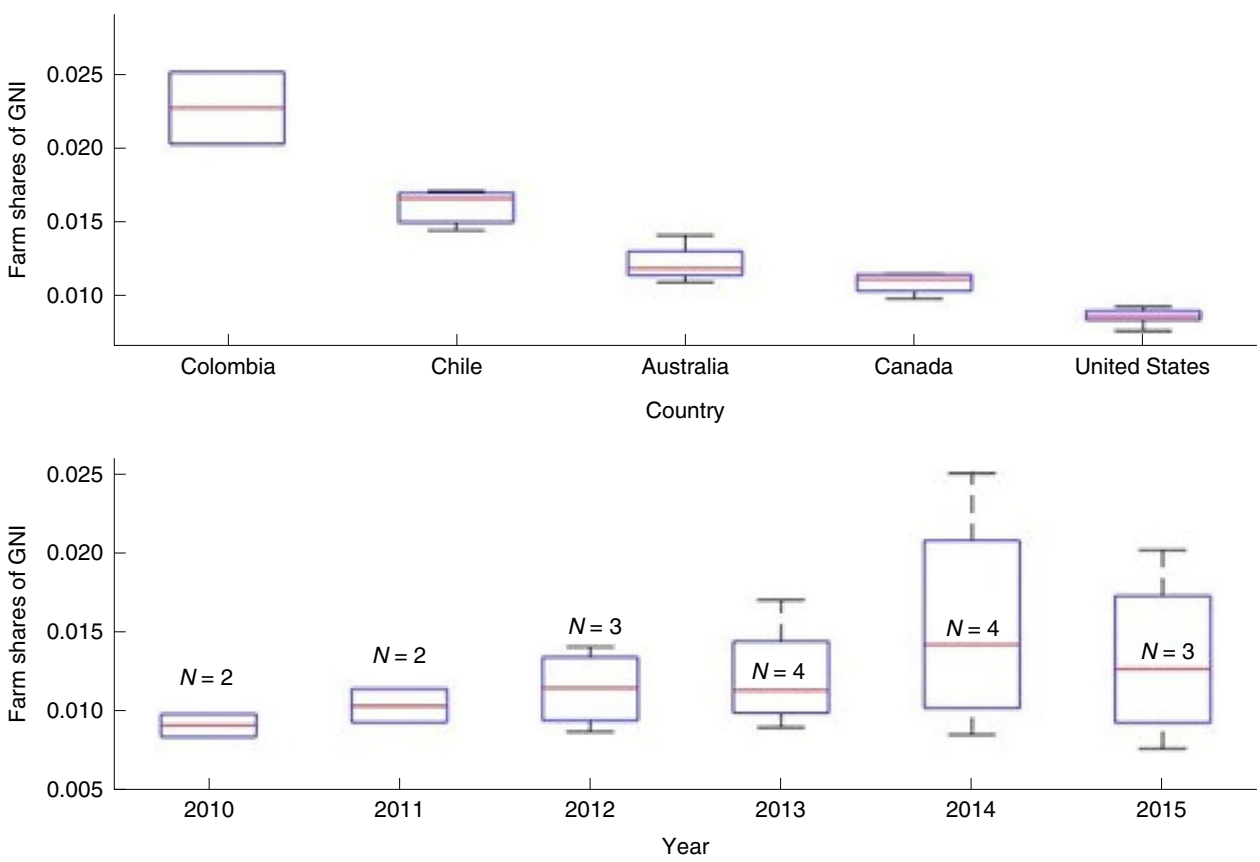

Fig. 2 | Farm shares of GNI. The top panel shows box and whisker plots of farm shares of nominal GNI for selected countries over the period $2010-2015$. The farm shares are calculated as the product of food-at-home expenditures and the multiplier fah series divided by GNI. The same values are plotted in the bottom panel but grouped by year. The red line in each box is the median. The bottom and top edges of each box are the 25th and 75th percentiles, respectively. The two horizontal lines outside the boxes indicate the maximum and minimum values. $N$ is the number of country observations available for that year.

is clearly reflected in the fact that, on average, nearly three-quarters of the value addition reflected in domestic consumers' food purchases occurred post-farmgate. Given even more spatially elongated global FVCs that add transport, financing and marketing costs, the farm share of consumer food expenditures on globally traded food and beverages is almost surely even lower.

When we supplement the fah series with broader measures so as to add additional observations, the farm share falls further, as one would expect. Ideally, one would want to complement the fah measure with a similar food away from home (fafh) measure, that is, food expenditures in restaurants and other venues, as distinct from food purchased to prepare and consume at home. That conceptually appealing measure is not currently computable from publicly available SNA series. The mean farm share of a broader measure of food and tobacco at home (ftah) is $0.23(0.06)$ across 37 countries (Supplementary Table 2), reflecting the relatively greater processing of tobacco than of most food products. Likewise, the farm share of food and accommodations away from home (faafh) - which aligns the purchases of food through the food service industry with fah purchases through retailers (see Methods for details)-averaged 0.07 (0.06) across 64 countries (Supplementary Table 2), reflecting both the added value addition in food service for delivery to consumers away from their homes and the inclusion of accommodation services due to the nature of aggregation in the OECD data. The inclusion of accommodation services seems a tolerable distortion in order to obtain far more observations because food represents the vast majority of faafh, even in high-income countries such as the United States, and the fafh share of faafh varies relatively little over time (Supplementary Fig. 1 and Supplementary Table 3).

Although the time series we could construct from available data is short, just 2005-2015, we can identify not only the average share of farm versus post-farmgate revenues in consumer food expenditures but also time trends in the indicators. Currently, the ERS food dollar series offers the only extended time series available in any country. Over the 1947-2017 period, the farm share of US consumer total food expenditures has fallen from 46 to $15 \%$ as per capita incomes grew by an average of roughly $2 \%$ annually, the population urbanized heavily and agricultural land productivity increased by an average of $>1 \%$ annually (Fig. 3 ).

This pattern of declining farm share of consumer food expenditures is apparent in the new global food dollar series as well. We pool the constructed fah, ftah and faafh data to estimate multivariate regression models to illustrate how the global food dollar series correlates with key development indicators such as income and agricultural productivity (see Methods for details, Supplementary Table 4 for variables and data sources, Supplementary Table 5 for results and Supplementary Information for estimation code). In the baseline regression specification, every doubling of per capita real income is associated with a reduction in the farm share of domestic consumer food expenditures by an estimated 5.4 percentage points. The negative association between income and the farm share of consumer food expenditures is robust to a variety of controls, for period and/or country fixed effects, time trends and other explanatory variables (see Supplementary Information for details).

We use the multivariate regression results to simulate farm shares of fah for selected countries for the period 2015-2030 (Fig. 4). Given OECD country-specific forecasts of real income growth rates, and assuming continuation of recent agricultural land productivity growth rates, the farm share of consumer food expenditures falls rapidly in fast-growing, middle-income countries such as China and India, and more slowly in higher-income, slower-growing countries such as the United States, Korea or Brazil. This pattern is broadly consistent with the longer-run pattern apparent in the US data, and as economic theory predicts. Farm output and revenues grow as consumers become wealthier and more urban. Yet, at the same time, the farm share of the food economy steadily shrinks because post-farmgate FVC value addition grows even faster than farm output, as consumer demand for higher quality and more expensive packaging, preparation and so on grows with real income (Figs. 3 and 5). Today's low- and middle-income countries should therefore 


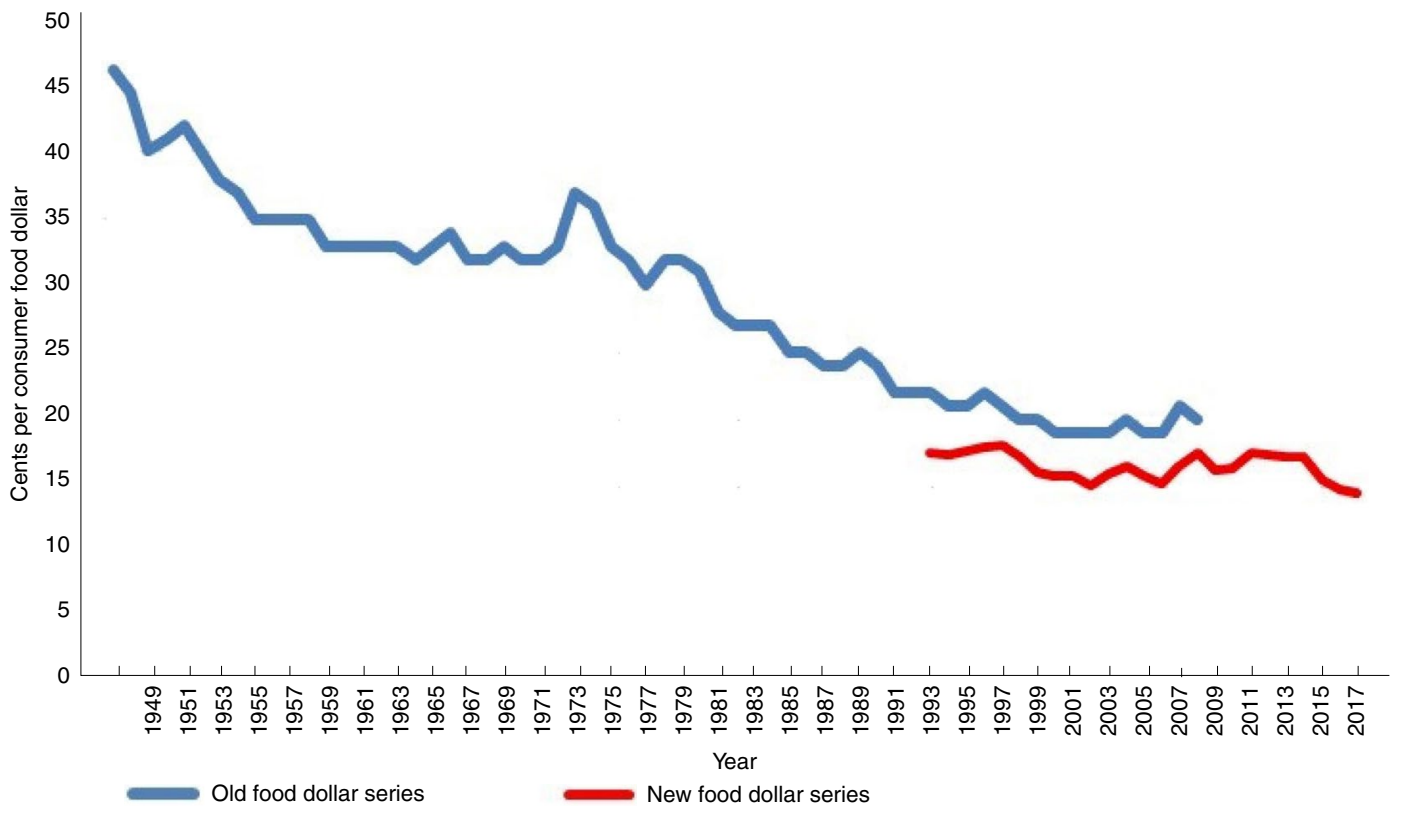

Fig. 3 | Farm share of US consumer food expenditures. As reported in the USDA ERS food dollar series, the revenue share of consumer food expenditures has declined fairly consistently for 70 years. Data are from the USDA ERS. See the source ERS study (https://www.ers.usda.gov/publications/ pub-details/?pubid=44827) for technical details on the construction of the original ('old') series and the new one introduced in 2011. The new series is, on average, 3.5 cents per dollar lower than the old series over the 16 years of overlapping coverage. US real per capita incomes grew roughly $2 \%$ annually over this period (https://fred.stlouisfed.org/series/A939RX0Q048SBEA).

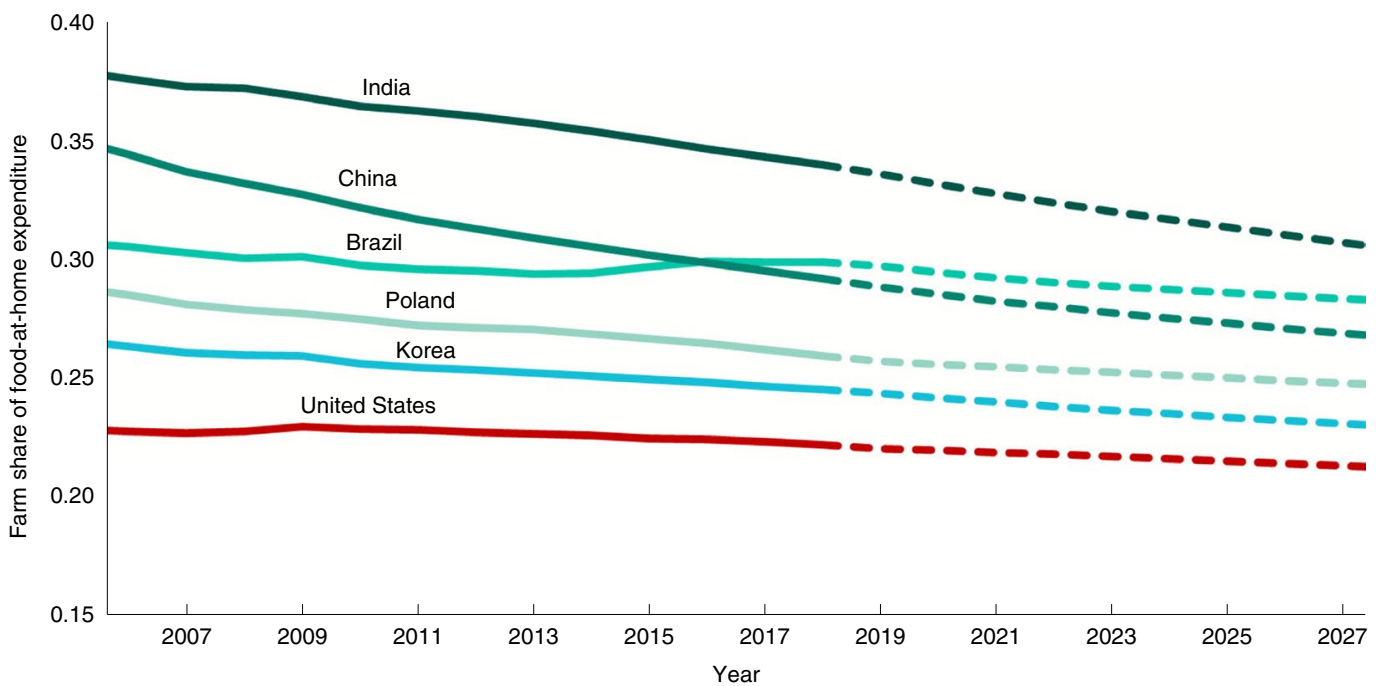

Fig. 4 | Farm share of at-home food expenditures for selected countries, 2005-2030. Farm shares for the period 2005-2018 (solid line) are calculated from the multivariate regression model (see Supplementary Information) using actual real GDP per capita for the years 2005-2018 (purchasing power parity adjusted, constant 2011 terms) and actual, inflation-adjusted agricultural land productivity for the years 2005-2016 (constant 2004-2006 terms). Agricultural productivity for the years 2017 and 2018 is assumed to grow at the average rate from 2005 to 2016. Projections of farm shares for the period 2019-2030 (dashed lines) are calculated from the econometric model (see Supplementary Information), using the OECD's GDP per capita long-term forecast (downloaded from https://data.oecd.org/gdp/real-gdp-long-term-forecast.htm\#indicator-char) and the 2005-2016 average agricultural land productivity growth rate. In the regression model, the number of observations in each year is $64,64,64,66,64,93,81,83,87,86$ and 92 for the years 2005-2015, respectively.

expect a disproportionately rapid expansion of the post-farmgate FVC in the future as primary agricultural production expands to meet growing consumer demand.

The partial correlation coefficient estimate relating agricultural land productivity to the farm share of consumer food expenditures is statistically insignificant in our regression analyses no matter the specification, underscoring that the steady decline in the farm share of consumer food expenditures is associated mainly with consumer income (and associated demographic) effects. We note, however, that this is a short time series and that given the lack of 

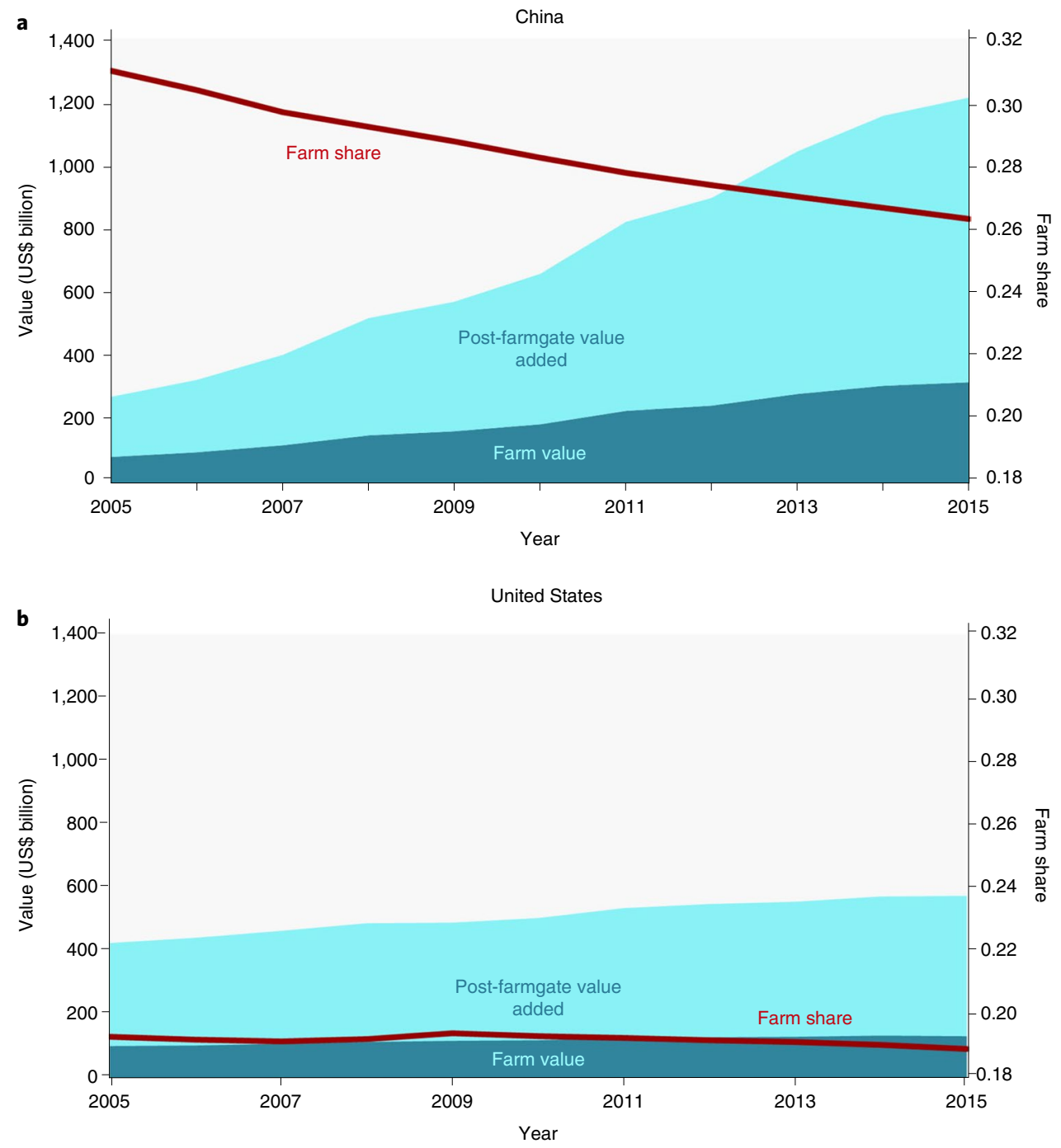

Fig. 5 | Food, tobacco, agriculture and forestry at-home expenditures in the United States and China. a,b, Away from home expenditures are not included. In both panels, the left axis shows the farm value (dark blue) and the post-farmgate value addition (light blue, both in billion current US\$). The right axis shows the percentage farm share of total food, tobacco, agriculture and forestry at-home expenditures (red line).

internationally comparable data on FVC concentration, we cannot control for the possible associations with changing market structure and (anti-)competitive pressures.

\section{Discussion}

These descriptive statistics cannot directly answer causal questions. However, they suggest useful hypotheses for further investigation. For example, these patterns reflect two empirical regularities of food economies. First, consumer income growth, relocation to towns, farther from farms, and labour specialization that renders more consumers unable to process agricultural feedstocks into edible, safe foods together combine to shift demand patterns. People's willingness to pay for non-nutritive food attributes-including appearance, safety and variety that farmers influence, but especially post-farmgate services arising from packaging, preparation, preservation, quality control, storage, transport and so on-grows far faster than their demand for nutrient intake embodied in the commodities that primary producers generate. Food services away from home grow especially quickly as higher wages and salaries, along with the increased prevalence of households in which all adults work outside the home, drive up the opportunity cost of time, making eating out or the purchase of ready-to-eat foods ever more attractive.
Second, consumer demand for food, especially for nutrients, is relatively price-inelastic. That is, human physiology constrains variation in consumption such that it cannot be sustained at either zero or uncountably high volumes, no matter the price. As a result, on-farm productivity gains generally drive down farmgate prices. And because consumer demand becomes less price-sensitive as incomes grow, the farmgate price effects of productivity growth increase in magnitude as countries develop, unless they can tap global markets.

Other explanations could reinforce these two demand-side explanations. For example, if a market segment becomes highly concentrated in a few firms, any collusive, monopolistic, or monopsonistic pricing strategies that may arise as a result could elevate consumer prices, suppress producer prices, or both, although there are specific circumstances when the opposite could occur, at least in the short run $^{19}$. Together, these consumer and firm behavioural mechanisms underpin the fundamental economic logic driving steady growth in post-farmgate value addition and decline in the farm share of consumer food expenditures, even as agricultural output and farm earnings expand.

Non-monetary impacts. The centrality of the post-farmgate FVC obviously transcends the food sector's economic footprint 
represented by monetary measures. As the global coronavirus pandemic has made clear, food system disruptions commonly originate in the post-harvest value chain, in response to rapid shifts in consumer demand patterns and logistical constraints to adapting to those changes, rather than in farm-level production shocks. But we hypothesize that just as scholars and policymakers commonly overlook the intermediate links in the value chain as they focus on the primary producer and consumer ends, so too do people underappreciate the impacts of FVC intermediaries on the sector's overall health, environmental and labour footprints. As post-farmgate FVCs grow in the years ahead, so will those environmental and social spillover effects.

There is already growing agreement that the most unhealthy foods are largely ultra-processed products that are high in such ingredients as salt, sugars and saturated fats $\mathrm{s}^{20}$, that is, manufactured post-farmgate. In the average American diet, for example, only about $30 \%$ of calorie intake comes from non-processed or mildly processed foods ${ }^{21}$. Ultra-processed foods also occupy a rapidly rising share of diets in developing countries as consumers seek greater convenience and safety ${ }^{22}$. The environmental impacts of ultra-processed foods have not been properly accounted for in many studies, often considering the effects of the primary commodities used for production and disregarding the processing, packaging and distribution stages ${ }^{23}$.

Likewise, the post-farmgate food processing sector is a major source of single-use plastics ${ }^{24}$, greenhouse gas emissions ${ }^{14,25}$, water use and effluent discharge. Although there is a burgeoning body of literature and interest in the environmental impacts of food demand both in the United States ${ }^{26-29}$ and globally ${ }^{1,30-32}$, few studies have yet carefully apportioned the environmental impacts of the food system between on-farm primary production and post-farmgate activities. We hypothesize that some of the food system impacts people most worry about follow the money; they are concentrated largely in the post-farmgate stages of the FVC. This question merits more research and can be facilitated by an environmentally extended food dollar framework that incorporates supply chain analysis. This approach $^{14,15}$ provides a clean and precise method to organize the decomposition of both value added and environmental impacts into supply chain stages and allows for application of, for example, emission intensities by type of product and source of emissions for precisely defined stages along each commodity supply chain.

The labour market impacts follow a similar pattern. For example, in 2017, of 21.6 million full- and part-time jobs related to the agricultural and food sectors in the United States, direct on-farm employment accounted for only 2.6 million (about 12\%). This is broadly in line with the farm share of consumer food expenditures. Meanwhile, the food service industry alone accounted for roughly five times as many jobs ${ }^{33,34}$. Therefore, the food system's labour market impacts come almost entirely from post-farmgate value chains, although the popular narrative around the impacts of immigration policy on the workforce and so on focuses heavily on farms. The global food dollar series can be extended to include employment data to examine labour market impacts of evolving FVCs.

As this new global food dollar data series shows, post-farmgate FVC actors account for the overwhelming majority of economic activity in food systems. Once more disaggregated SNA data-or a time series of social accounting matrices - can be compiled, this global food dollar method could be usefully expanded to cover a broader universe of (especially low-income) countries for which data are not currently available. This approach can also be disaggregated to analyse specific food product categories (for example, fruits and vegetables, meats, dairy, grains and so on), merged with market structure data to explore whether concentrating market shares might cause redistribution of economic returns within the FVC, used to compare global versus domestic FVCs, and adapted to unpack the use of specific resources within the integrated environmental and economic accounts (for example, labour, energy, water, greenhouse gas emissions and so on). Finally, future work can incorporate pre-farmgate segments of the supply chains (for example, seed, fertilizer and so on) to examine how the evolution of food supply chains influences the value captured by farmers and input suppliers. Such extensions would enable more consistent measurement of FVCs' ecological, economic and social footprint on national, regional and global scales, as well as more precise targeting of appropriate entry points for policy interventions.

The new global food dollar method and proof-of-concept data set we introduce demonstrate the feasibility of generating systematic, cross-nationally comparable, economy-wide FVC decompositions. Our demonstration with food expenditures data suggests that the post-farmgate portion of FVCs merits far more in-depth research and policy attention as analysts and policymakers work to foster necessary transformations in local and global FVCs to advance the SDGs. The same is probably true for non-monetary impacts that can likewise be allocated across FVC segments.

\section{Methods}

The global food dollar method we present answers the question 'what is the average share of domestic consumer food purchases received over a calendar year by farmers from the sale of agricultural commodities (excluding farm-to-farm sales) they produced to accommodate these food purchases, and how has this share changed over time?' The complement, or remainder, is the post-farmgate FVC share. We estimate the domestic farm share of domestic consumer expenditures on domestically produced fah, ftah and faafh using an input-output multiplier model.

Ideally, we would focus on just fah-not including tobacco-and on fafh-not including accommodations. Unfortunately, the harmonized national inputoutput and use tables data do not separate consumer food and accommodations expenditures away from home ${ }^{16}$. They also permit construction of fah for only ten countries over the 2005-2015 period and only one of them (the United States) for the whole period, another with just five years' data (Korea) and just two (Australia and Canada) with three years' data (Supplementary Table 2). We, therefore, supplement analysis of the 34 country-year fah observations that can be constructed from the OECD data with analyses that add an additional 163 and 704 country-year observations of ftah and faafh, respectively (Supplementary Table 2), using statistical controls for the different measures to infer broader patterns in the farm share of consumer food expenditures. Supplementary Fig. 1 shows that the ratio of fafh expenditures to faafh in the United States is consistently in the 84-86\% interval over the period 2005-2015. Moreover, Supplementary Table 3 reports the same ratio for selected years between 2008 and 2016 for a group of 12 countries and shows that for this very limited sample, the fafh/faafh ratios for each country change very little over time. This suggests that faafh is a reasonable, implementable measure to include in the analysis in order to substantially expand the sample size. The next generation of the global food dollar data series would be greatly enriched by access to more disaggregated data that permit construction of more precise fah and fafh series for a larger number of countries and years.

Measuring the farm share of food expenditures. The global fah, ftah and faafh farm share series are derived from a type I input-output multiplier model commonly used to trace out the interrelationship among distinct economic sub-sectors in complex economies ${ }^{35}$. Each series is compiled from Revision 4 of the OECD harmonized national input-output tables (IOT) ${ }^{16}$. Additionally, personal consumption expenditure vectors for both the fah and ftah farm share series are compiled from the accompanying country 'Use' tables reported in both basic and purchaser prices (Supplementary Tables 40 and 43 from Revision 4 of the OECD Annual National Accounts, available for download at https://stats.oecd.org/Index.aspx). Use tables are available for a subset of countries covered by the IOT database, and in most cases for only a subset of the years. For this reason, we have fewer fah and $\mathrm{ftah}$ observations than faafh observations because the latter are measured directly from the IOT data. The data sources are shown in Supplementary Table 1. Note that we exclude Ireland, Luxemburg and Turkey, for which the OECD reports IOT and Use tables, because of anomalies in their series that render those data unreliable for this exercise. Among countries where 'food and tobacco' expenditure data is available in both basic and purchaser prices, we find the Ireland data problematic and so exclude it from our analysis. Whereas purchaser price mark-ups range between 35 and 154\% in other countries, data for Ireland show mark-ups of 585, 362 and 441\% in years 2010, 2011 and 2015 , respectively. In Luxemburg, the farm shares are $<1 \%$, given the unique characteristics of this country. Turkey has only one observation for 2012 and the estimated farm share is implausibly high ( $52 \%$; see Supplementary Table 2 for the farm shares calculated for these countries).

The basic model. The basic multiplier model ${ }^{35}$, compiled directly from IOT data, consists of a symmetric industry (I) by industry transaction matrix, $Z$, an industry 
by sector (S) final demand (gross domestic product (GDP) plus imports) matrix, $Y$, and a factor (F) by industry value added (gross domestic income plus imports) matrix, $V$. More specifically, sector accounts (columns) consist of household personal consumption expenditures $\left(Y_{\mathrm{I}, \mathrm{pcc}}\right)$, private and public direct investment $\left(Y_{\mathrm{I}, \mathrm{inv}}\right)$, government consumption expenditures $\left(Y_{\mathrm{I}, \mathrm{gov}}\right)$ and gross exports $\left(Y_{\mathrm{I}, \text { exp }}\right)$. Factor accounts (rows) consist of the various claimants to industry value added (pre-income tax), labour $\left(V_{\mathrm{l}, \mathrm{I}}\right)$, governments $\left(V_{\mathrm{g}, \mathrm{I}}\right)$ in the form of output taxes and fees net of subsidies, property owners $\left(\mathrm{V}_{\mathrm{p}, \mathrm{I}}\right)$ such as proprietors and stockholders, and international suppliers $\left(V_{\mathrm{m}, \mathrm{I}}\right)$. In our notation, matrices and vectors are specified in italic font with upper-case letters and bold font with lower-case letters, respectively; sets and set elements appear with upper- and lower-case letters/ numbers, respectively; scalars are denoted in italicized lower-case letters/numbers; a prime (') denotes a transposed vector or matrix; a double prime (") denotes a diagonalized vector; ()$^{-1}$ represents the matrix inversion operator; and $\mathbf{j}$ is a unit vector of varying dimensions.

The data system is organized as per equation (1) and described in detail in Supplementary Table 1:

$$
\begin{aligned}
& {[Z][Y]} \\
& {[V][0]}
\end{aligned}
$$

Summation across any row $i \in I,\left(Z_{i, I} \mathbf{j}_{I}\right)+\left(Y_{i, s} \mathbf{j}_{s}\right)$, yields total use of industry (i) output. Summation down the corresponding column, $\mathbf{j}_{\mathrm{I}}^{\prime} Z_{\mathrm{I}, \mathrm{i}}+\mathbf{j}_{\mathrm{F}}^{\prime} V_{\mathrm{Fi}}$, yields total supply (domestic plus imports) of industry output. By construction, supply equals use for each industry market $i \in I$, and both equal the import inclusive gross industry output, denoted $\mathbf{x}$.

In the type I input-output multiplier model, only inter-industry transactions are endogenous. Final demand is considered an exogenous injection, or input, into the system. Industry value added is a leakage, or output, of the system and is determined following Walras's law. To compile the multiplier model, the exogenous accounts, $Y$ and $V$, are reduced to vectors $-\mathbf{y}=Y \mathbf{j}, \mathbf{v}=\mathbf{j}^{\prime} V$ - and the endogenous inter-industry transaction matrix is normalized column-wise by its import inclusive gross industry output $-A=Z\left(\mathbf{x}^{\prime \prime}\right)^{-1}$. This facilitates derivation of the multiplier model as follows:

$$
A \mathbf{x}+\mathbf{y}=\mathbf{x} \leftrightarrow \mathbf{y}=\left(\mathbf{j}^{\prime \prime}-A\right) \mathbf{x} \leftrightarrow\left(\mathbf{j}^{\prime \prime}-A\right)^{-1} \mathbf{y}=\mathbf{x} \leftrightarrow L \mathbf{y}=\mathbf{x}
$$

In equation (2), the $L$ matrix, which is interchangeably referred to as the Leontief or total requirements matrix, produces the industry output multipliers for total final demand. As output multipliers are fixed coefficients, the system is linear homogenous, meaning any multiple of total final demand, say $2 y$, requires the same multiple for gross output, $2 \mathbf{x}$.

Denote $\mathbf{s}^{\text {tah }}$ as the food-share vector. It contains share measures of each element in the final demand vector, which represents fah expenditures, such that $\left(\mathbf{s}^{\text {tah }}\right)^{\prime \prime} \mathbf{y}=\mathbf{y}^{\text {fah }}$. If we assume the supply and use of agricultural industries are fully depicted in the first column and row of the Leontief matrix, the gross agricultural share (gfs) of fah dollars is routinely measured as:

$$
\mathrm{gfs}^{\mathrm{fah}}=L_{1,1} \mathbf{y}^{\mathrm{fah}}\left(\mathbf{j}^{\prime} \mathbf{y}^{\text {fah }}\right)^{-1}=\mathbf{x}_{1}^{\mathrm{fah}} / \mathbf{y}^{\text {fah }}
$$

To eliminate double counting due to both direct and indirect farm-to-farm sales, net farm sales linked to fah spending are measured as (denote non-agricultural industries as subset I). More generally, when the subset of agriculture industries span more than a single row/column pair, denoted by $\Omega$, then $\left.\mathrm{nfs}^{\mathrm{fah}}=\mathbf{j}_{\Omega}^{\prime}\left\{\mathbf{j}_{\Omega}^{\prime \prime}-\left(A_{\Omega, \Omega}+A_{\Omega, \underset{\sim}{\mathrm{I}}} \underset{\sim}{\mathrm{I}} \underset{\sim}{\mathrm{I}} A_{\underset{\sim}{\mathrm{I}}, \Omega}\right)\right\} \mathbf{x}^{\mathrm{fah}} / \mathbf{y}^{\mathrm{fah}}\right)$ :

$$
\mathrm{nfs}^{\text {fah }}=\left\{1-\left(A_{1,1}+A_{1, \mathrm{I}} \sim_{\mathrm{I}, \mathrm{I}} \sim_{\sim} A_{\sim}, 1\right)\right\} \mathbf{x}_{1}^{\text {fah }} / \mathbf{y}^{\text {fah }}=\mathbf{x}_{1}^{\text {fah_net }} / \mathbf{y}^{\text {fah }}
$$

The 'fah_net' superscript indicates the elimination of farm-to-farm direct and indirect sales from the measure of farm industry outputs.The measure in equation (4) includes food expenditures on imports in the denominator and imported farm industry outputs in the numerator. To obtain an estimate for the domestic farm share of expenditures on domestically produced food in the basic model, we denote $\mathbf{s}^{\mathrm{dx}}$ as a vector for the measure of domestic shares of the import inclusive gross industry output vector:

$$
\mathbf{s}^{\mathrm{dx}}=\left(\mathbf{x}^{\prime \prime}\right)^{-1}\left(\mathbf{x}-V_{\mathrm{m}, \mathrm{I}}^{\prime}\right)
$$

From this measure, the domestic portion of both food expenditures and the associated net farm outputs is obtained:

$$
\operatorname{dnfs}^{\text {fah }}=\mathbf{s}_{1}^{\mathrm{dx}} \mathbf{x}_{1}^{\text {fah_net }}\left(\mathbf{s}^{\mathrm{dx} /} \mathbf{y}^{\text {fah }}\right)^{-1}
$$

In equation (6), 'dnfs' represents the domestic net farm share of food-at-home dollars. Identical calculations can be made for both the $\mathrm{ftah}\left(\mathrm{dnfs}^{\text {ftah }}\right)$ and faafh $\left(\operatorname{dnfs}^{\text {faafh }}\right)$ dollars.

The extended food dollar model. Two modifications to the basic model are required to accurately measure the domestic net farm share. Both modifications require no additional data. By convention, retail expenditures on food are treated as several transactions in the IOT: expenditures on food commodities ('food') and simultaneous expenditures on retail and freight 'margin' services ('margin'). This treatment makes the calculation in equation (6) routine. However, also by convention in the IOT, when food is acquired through a food and accommodations establishment, the only transaction recorded is the purchase of a non-traded good ('foodservice'). In this case, the acquisition of the food is recorded as an intermediate transaction of the foodservice industry. The implication of this accounting practice is that equation (6) will fail to net out any imported food purchases by the foodservice industry. The work-around for this is to decouple the foodservice industry into two: 'accommodations and foodservices' (afs) and fafh. This change aligns the treatment of fafh purchases with those for fah purchases. For industry outlays it is done as follows (where initially $Z^{\text {fdd }}=Z, V^{\text {gfd }}=V$ and $\mathbf{b}_{\text {food }}$ is a $[0,1]$ binary vector with unit values only in food output rows):

$$
Z_{\mathrm{I}, \text { fafh }}^{\mathrm{gfd}}=\mathbf{b}_{\text {food }}^{\prime \prime} Z_{\mathrm{I}, \mathrm{afs}}
$$

$$
V_{\mathrm{F}, \mathrm{fafh}}^{\mathrm{gfd}}=0
$$

$$
\begin{gathered}
Z_{\mathrm{I}, \mathrm{afs}}^{\mathrm{gfd}}=\left(1-\mathbf{b}_{\mathrm{food}}^{\prime \prime}\right) \cdot Z_{\mathrm{I}, \mathrm{afs}} \\
V_{\mathrm{F}, \mathrm{afs}}^{\mathrm{gfd}}=V_{\mathrm{F}, \mathrm{afs}} \\
\mathbf{x}^{\mathrm{gfd}}=\left(\mathbf{j}_{\mathrm{I}}^{\prime} Z^{\mathrm{gfd}}+\mathbf{j}_{\mathrm{F}}^{\prime} V^{\mathrm{gfd}}\right)^{\prime}
\end{gathered}
$$

For intermediate and final use of outputs (where initially $Y^{\mathrm{gtd}}=Y$ ):

$$
\begin{gathered}
Z_{\mathrm{fafh}, \mathrm{I}}^{\mathrm{gdd}}=\alpha_{\mathrm{fafh}}^{\mathrm{gfd}} Z_{\mathrm{afs}, \mathrm{I}}^{\mathrm{gfd}} \\
Y_{\mathrm{fafh}, \mathrm{S}}^{\mathrm{gfd}}=\alpha_{\mathrm{fafh}}^{\mathrm{gfd}} Y_{\mathrm{afs}, \mathrm{S}}^{\mathrm{gfd}} \\
Z_{\mathrm{afs}, \mathrm{I}}^{\mathrm{gfd}}=\left(1-\alpha_{\mathrm{fafh}}^{\mathrm{gfd}}\right) Z_{\mathrm{afs}, \mathrm{I}}^{\mathrm{gfd}} \\
Y_{\mathrm{afs}, \mathrm{S}}^{\mathrm{gfd}}=\left(1-\alpha_{\mathrm{fafh}}^{\mathrm{gfd}}\right) Y_{\mathrm{afs}, \mathrm{S}}^{\mathrm{gfd}} \\
\alpha_{\mathrm{fafh}}^{\mathrm{gfd}}=\mathbf{x}_{\mathrm{fafh}}^{\mathrm{gfd}}\left(\mathbf{x}_{\mathrm{afs}}\right)^{-1}
\end{gathered}
$$

Equation (16) shows the share of gross output for the accomodation and food services industry that is accounted for by the value of food purchases by this industry. This share factors into the calculations for equations (12) to (15). The computations in equations (5) and (6) serve to identify the domestic share of all transactions linked to food expenditures, based on the domestic share of total domestic plus import availability. However, another accounting convention in the IOT is to exclude international transshipments (where shipments into a country represent an intermediate destination) from both the import and export accounts. This implies exports are entirely sourced from domestic production and imports are entirely absorbed by domestic uses. To ensure this is represented in the multiplier model $\left(L^{\text {fdd }}\right)$, we add an export assembly (ea) industry that consolidates all production for the export market, as follows:

$$
\begin{gathered}
Z 2^{\mathrm{gfd}}=\left[\left(Z^{\mathrm{gdd}}-A^{\mathrm{gfd}}\left(Y_{\mathrm{I} \cdot \exp }^{\mathrm{gdd}}\right)^{\prime \prime}\right) \|\left(A^{\mathrm{gfd}} \cdot Y_{\mathrm{I} \cdot \exp }^{\mathrm{gfd}}\right)\right] / / 0_{\mathrm{I}}^{\prime} \\
V 2^{\mathrm{gfd}}=\left(V^{\mathrm{gfd}}-W^{\mathrm{gfd}}\left(Y_{\mathrm{I} \cdot \exp }^{\mathrm{gfd}}\right)^{\prime \prime}\right) \|\left(W^{\mathrm{gfd}} \cdot Y_{\mathrm{I} \cdot \exp }^{\mathrm{gfd}}\right) \\
Y 2_{\mathrm{I} \cdot \exp }^{\mathrm{gfd}}=0 Y_{\mathrm{I} \exp }^{\mathrm{gfd}} /\left(\mathbf{j}_{\mathrm{I}}^{\prime} Y_{\mathrm{I} \cdot \exp }^{\mathrm{gfd}}\right) \\
x 2^{\mathrm{gfd}}=\left(\mathbf{j}_{\mathrm{I}}^{\prime} \cdot Z 2^{\mathrm{gfd}}+\mathbf{j}_{\mathrm{F}}^{\prime} V 2^{\mathrm{gfd}}\right)^{\prime}
\end{gathered}
$$

where $W^{\mathrm{gfd}}=V^{\mathrm{gdd}}\left(\left[\mathbf{x}^{\mathrm{gfd}}\right]^{\prime \prime}\right)^{-1}, \|$ denotes a column concatenation and // denotes a row concatenation.

Without specific data to distinguish utilization of domestic production and imports by intermediate and final market activities, we adopt the convention of pooling imports with domestic production by adding an imports row vector to the $V$ matrix specified above. When computing total supply, this pooling approach assumes all activities utilize a mix of domestic and import products equal to their respective shares of total availability. The steps outlined in equations (17)-(20) 
ensure that imports are not re-exported (transshipped) and that (on average) the mix of domestic production and import utilization across all activities is correctly represented. When more detailed data are available to distinguish domestic and import utilization by activity, it would be preferable to specify a separate import utilization matrix.

Derivation of food expenditures. The final step to compile the three farm share series is to develop the vectors $\mathbf{s}^{\text {fah }}, \mathbf{s}^{\text {ftah }}$ and $\mathbf{s}^{\text {faafh }}$. Of these, the last is routine $-\mathbf{s}_{\mathrm{i}}^{\text {faafl }}$ $=1 \forall \mathrm{i} \in$ (fafh, afs); 0 otherwise. Supplementary Table 2 lists all country-year pairs with the resulting $\mathbf{s}^{\text {faafh }}$ estimates. For the two at-home expenditure vectors there are two calculations that require additional data beyond the IOT. The first is to determine what share of personal consumption expenditures on 'agriculture, forestry and fishing' and on 'food products, beverages and tobacco' (denoted the 'food' subset) represent food purchases. The second is to calculate the additional margin costs for retail and freight services (the 'margin' subset) for each food purchase. For both calculations, the data required are available from Supplementary Tables 40 and 43 (country use tables in basic and purchaser prices, respectively) of the OECD Annual National Accounts (Revision 4), available from the same source as the IOT.

Recall that the food industry subset of the IOT is a grouping of six industries: agriculture, forestry, fisheries, food, beverages and tobacco. The first and last three industries (that is, agriculture, beverages, food and tobacco) form two distinct IOT industry groups. For the Use tables, there is not a uniform set of industries across all countries. Some countries have less detailed industry groups and others have more detail. Those with more detail fall into two groups: those allowing for netting out of forestry and tobacco from a food subset, denoted food1, and those only allowing a netting out of forestry, denoted food 2 , such that food $1 \subset$ food $2 \subset$ food

For the food expenditure share calculation $\left(\mathbf{s}^{\mathrm{fah}}\right)$, we use all country-year data points containing the food 1 industry detail. Ten countries were identified as having disaggregated consumption expenditure Use table data containing the food 1 industry detail in both basic (yb1) and purchaser (yp1) prices that facilitated the netting out of forestry and tobacco expenditures (Supplementary Table 2 lists all country-year pairs with the food 1 data and resulting $\mathbf{s}^{\text {fah }}$ estimates):

$$
\mathbf{s}^{\mathrm{fah}}=\left(\mathbf{b}_{\text {food }}^{\prime \prime} \mathbf{y b} 1\right)^{-1}\left(\mathbf{b}_{\text {food } 1}^{\prime \prime} \mathbf{y b} 1\right)
$$

Although agricultural industry non-food consumer products remain in the resulting $\mathbf{y}^{\text {fah }}$ expenditure vector, generating some upward bias in $\mathbf{y}^{\text {fah }}$ as an estimate of the farm share of consumer food expenditures, we consider this a reasonable estimate for the farm share of food-at-home expenditures.

For the food and tobacco expenditure share calculation $\left(\mathbf{s}^{\mathrm{ftah}}\right)$, we use all country-year data points containing the food 2 industry detail. Beyond the ten countries for which $\mathbf{s}^{\text {fah }}$ estimates are feasible, an additional 29 countries were identified as having disaggregated consumption expenditure Use table data containing the food 2 industry detail in both basic (yb2) and purchaser (yp2) prices that facilitated netting out forestry and tobacco expenditures (Supplementary Table 2 lists all country-year pairs with the food 2 data and resulting $\mathbf{s}^{\text {ftah }}$ estimates):

$$
\mathbf{s}^{\mathrm{ftah}}=\left(\mathbf{b}_{\text {food }}^{\prime \prime} \mathbf{y b} 2\right)^{-1}\left(\mathbf{b}_{\text {food } 2}^{\prime \prime} \mathbf{y b} 2\right)
$$

This calculation produces a reasonable estimate for the farm share of at-home food and tobacco expenditures.

For the margin cost calculations, total combined (retail and wholesale) trade and transportation margin costs of each food-related (food) transaction $-\mathbf{y}_{\text {food }}^{\text {fah }}, \mathbf{y}_{\text {food }}^{\text {ftah }}$ and $\mathbf{y}_{\text {food }}^{\text {faafh }}$-are measured as the difference in value as measured in purchaser prices (yp) and basic prices (yb). This total is allocated to each margin industry in proportion to their cost contributions to total personal consumption expenditures. Because margin industries also market consumer products, the portion of expenditures representing margin costs is measured as $\left(\mathbf{y b} \mathbf{b}_{\text {margin }}-\mathbf{y} \mathbf{p}_{\text {margin }}\right)$, and our target measure is:

$$
\begin{aligned}
& \mathbf{y}_{\text {margin }}^{\mathrm{fah}}=\left\{\mathbf{j}_{\text {food }}^{\prime}\left(\mathbf{y} \mathbf{p}_{\text {food }}^{\mathrm{fah}}-\mathbf{y} \mathbf{b}_{\text {food }}^{\mathrm{fah}}\right)\right\}\left(\mathbf{y} \mathbf{b}_{\text {margin }}-\mathbf{y} \mathbf{p}_{\text {margin }}\right) \\
& \left\{\mathbf{j}_{\text {margin }}^{\prime}\left(\mathbf{y} \mathbf{b}_{\text {margin }}-\mathbf{y} \mathbf{p}_{\text {margin }}\right)\right\}^{-1}
\end{aligned}
$$

The SAS code necessary to replicate these computations is included in the Supplementary Information.

Global food dollar farm share calculations versus price spreads. The global food dollar calculation of farm shares of total food expenditures necessarily differs from price spreads for specific commodities. The global food dollar method we present answers the question 'what is the average share of domestic consumers' food purchases received over a calendar year by farmers for the agricultural commodities they produced, and how has this share changed over time?' By comparison, price spread estimates offer comparisons of farmgate and retail prices for individual foods and groupings of individual foods-market baskets-that represent what a typical US household buys at retail in a year ${ }^{33}$. Price spreads can necessarily be made only for minimally processed products that do not combine different commodities, limiting their ability to represent the food economy as a whole. The global food dollar series, by comparison, provides an average across all food and beverage products combined, inclusive of the large share of consumer purchases of processed food products that blend commodities. For faafh, the global food dollar method also includes both purchases in retail food stores and purchases in food service establishments (for example, restaurants), where virtually all sales are of foods that combine commodities. In several high-income economies, food expenditures away from home are equal to or exceed food purchases for consumption at home.

Econometric estimation methods. To illustrate the usefulness of the global food dollar series, we use multivariate regression analyses to show how the post-farmgate share of food value addition correlates with key economic development indicators.

Data. We supplement the fah, ftah and faafh data, constructed following the methods above, with secondary data from the World Bank ${ }^{17}$ and the Food and Agriculture Organization ${ }^{36}$. An overview of the complete set of variables considered in the analysis as well as data sources are provided in Supplementary Table 4. We considered a number of variables that may affect the farm share of food expenditures. However, given the strong correlation among several candidate explanatory variables such as population, urbanization, electrification and agricultural labour productivity, we opted for a more parsimonious regression specification (Supplementary Table 5). In our multiple regression framework, we focus on indicators of economic development and agricultural productivity. We use the logarithm of GDP per capita (in constant US\$2011) to represent level of economic development and measure agricultural land productivity as the gross production value (in million US\$ in real terms) divided by agricultural land ( in 1,000 ha)

Methods. To analyse the relationship between the farm share and our explanatory variables of interest, we estimate regressions of the following general form:

farm_share $_{i t m}=\beta_{0}+\beta_{1} \ln (\mathrm{gdp})_{i t}+\beta_{2}$ ag_productivity $_{i t}+\beta_{3}$ type $_{i t m}+\delta_{i}+\tau_{t}+\epsilon_{i t m}$

where the dependent variable (farm_share) is the farm share of country $i$ in year $t$ for measure $m$ : $\mathrm{ftah}$, or faafh, with fah being the baseline, omitted type of measure. We include all three types of farm share due to the limited number of observations for fah and because each captures a common core component. We must necessarily assume that the difference across measures is constant across countries, time and the other covariates. With richer data than are presently available, one could relax and test that assumption. In an alternative specification of the regression, we exclude faafh estimates, thus focusing on only ftah and fah. For all regressions, we weight individual observations by the inverse of the number of total observations of measures per county. This is done to account for the fact that the number of farm share estimates varies across countries.

The variable $\ln (\mathrm{gdp})_{i t}$ refers to the logarithm of real GDP per capita in country $i$ in year $t$; and ag_productivity ${ }_{\text {it }}$ reflects agricultural land productivity in country $i$ in year $t$. The parameter $\delta_{i}$ represents country fixed effects, capturing time-invariant characteristics such as geographic location or traditional cuisine, $\tau_{t}$ represents year fixed effects that capture intertemporal variation common to all countries, such as global food price swings, and $\varepsilon_{i t}$ is the error term. In all regressions, we cluster standard errors at the country level. In order to make clear what effects these fixed effects controls have, we estimate and report several alternative specifications, where we do not include fixed effects (Supplementary Table 5, column 1), include only country fixed effects (Supplementary Table 5, column 2), country and year fixed effects (Supplementary Table 5, column 3) or time trends and country fixed effects (Supplementary Table 5, column 4). The same patterns hold if one runs the same regressions on just the much smaller set of fah and ftah series, restricting the analysis to consumer food expenditures at home (details available on request).

Results. We find that the farm share of domestic consumer food expenditures falls by $5.4 \%$, on average, with every doubling of per capita real income (Supplementary Table 5, column 1). When we add country fixed effects (column 2), the magnitude of the coefficient estimate on $\ln (\mathrm{gdp})$ shrinks dramatically and becomes statistically insignificantly different from zero, while the estimate regression intercept drops by roughly half, a statistically significant difference. These changes in the regression model with and without country fixed effects indicate that the observed pattern reflects more medium- to longer-run changes associated with cross-country differences in this relatively short panel than they do shorter, year-on-year fluctuations in incomes within a country over the course of the 11 years. Because dietary change is a slow process and the core underlying economic drivers of consumer demand for non-nutritive attributes appear universal ${ }^{9}$, we favour the pooled regression specification without country fixed effects.

The ftah series are consistently less than the fah series, by 2-4 percentage points, reflecting the greater processing of tobacco than food products, on average. The faafh series is consistently 19-20 percentage points lower than fah, partly because fafh has added service and facility rental costs and because of the inclusion of expenditures on accommodations in the national accounts data series assembled by OECD. The addition of year fixed effects (column 3 ) for year-on-year shocks common to all countries (for example, the global food price spikes of 2007-2008 
and 2010-2012) or time trends (column 4), has no significant effect on any of the parameter estimates.

Reporting Summary. Further information on research design is available in the Nature Research Reporting Summary linked to this article.

\section{Data availability}

Data can be retrieved from GitHub open data portal: https://fedscornell.github.io/ GlobalFoodDollar/. Source data are provided with this paper.

\section{Code availability}

Code to reproduce all results are available in the Supplementary Information, or from GitHub open data portal: https://fedscornell.github.io/GlobalFoodDollar/.

Received: 12 November 2020; Accepted: 20 April 2021;

Published online: 7 June 2021

\section{References}

1. Willett, W. et al. Food in the Anthropocene: the EAT-Lancet commission on healthy diets from sustainable food systems. Lancet 393, 447-492 (2019).

2. Food Systems Summit 2021 (United Nations, 2020); https://www.un.org/en/ food-systems-summit

3. Laborde, D., Martin, W., Swinnen, J. \& Vos, R. COVID-19 risks to global food security. Science 369, 500-502 (2020).

4. Barrett, C. B. Actions now can curb food systems fallout from COVID-19. Nat. Food 1, 319-320 (2020)

5. Minten, B., Murshid, K. A. S. \& Reardon, T. Food quality changes and implications: evidence from the rice value chain of Bangladesh. World Dev. 42, 100-113 (2013).

6. Minten, B., Tamru, S., Engida, E. \& Kuma, T. Ethiopia's Value Chain on the Move: The Case of Teff Ethiopia Strategy Support Program Working Paper No. 52 (International Food Policy Research Institute, 2013).

7. Reardon, T. et al. The quiet revolution in Asia's rice value chains. Ann. NY Acad. Sci. 1331, 106-118 (2014).

8. Canning, P. A Revised and Expanded Food Dollar Series: A Better Understanding of our Food Costs ERR-114 (US Department of Agriculture Economic Research Service, 2011).

9. Canning, P., Weersink, A. \& Kelly, J. Farm share of the food dollar: an IO approach for the United States and Canada. Agric. Econ. 47, 505-512 (2016).

10. Gardner, B. L. The farm-retail price spread in a competitive food industry Am. J. Agric. Econ. 57, 399-409 (1975).

11. Booker, C. A handful of companies make most of our food. We need to end big food mergers. CNN Business https://www.cnn.com/2019/07/25/ perspectives/cory-booker-antitrust-farmers/index.html (25 July 2019).

12. Handbook of National Accounting Studies in Methods Series F, No. 61, Rev. 1 (United Nations, International Monetary Fund, and Organisation for Economic Co-operation and Development, Integrated Environmental and Economic Accounting, 2003).

13. Berti, G. \& Mulligan, C. Competitiveness of small farms and innovative food supply chains: the role of food hubs in creating sustainable regional and local food systems. Sustainability 8, 616 (2016).

14. Hitaj, C., Rehkamp, S., Canning, P. \& Peters, C. Greenhouse gas emissions in the US food system: current and healthy diets. Environ. Sci. Technol. 53, 5493-5503 (2019)

15. Resource Requirements of Food Demand in the United States ERR-273 (US Department of Agriculture Economic Research Service, 2020).

16. Input-Output Tables (Organisation for Economic Co-Operation and Development, 2018); http://oe.cd/i-o

17. World Bank Open Data (World Bank, 2019); https://data.worldbank.org/

18. D’Odorico, P., Carr, J. A., Laio, F., Ridolfi, L. \& Vandoni, S. Feeding humanity through global food trade. Earth's Future 2, 458-469 (2014).

19. Meyer, J. \& von Cramon-Taubadel, S. Asymmetric price transmission: a survey. J. Agric. Econ. 55, 581-611 (2004).

20. Juul, F., Martinez-Steele, E., Parekh, N., Monteiro, C. A. \& Chang, V. W. Ultra-processed food consumption and excess weight among US adults. $B r$. J. Nutr. 120, 90-100 (2018).

21. Martínez Steele, E., Popkin, B. M., Swinburn, B. \& Monteiro, C. A. The share of ultra-processed foods and the overall nutritional quality of diets in the US evidence from a nationally representative cross-sectional study. Popul. Health Metr. 15, 6 (2017).

22. Popkin, B. M. \& Reardon, T. Obesity and the food system transformation in Latin America. Obesity Rev. 19, 1028-1064 (2018).
23. Seferidi, P. et al. The neglected environmental impacts of ultra-processed foods. Lancet Planet. Health 4, E437-E438 (2020).

24. Giacovelli, C. Single-Use Plastics: A Roadmap for Sustainability (Rev. 2) (United Nations Environment Programme, 2018); http://wedocs.unep.org/ handle/20.500.11822/25496

25. Camanzi, L., Alikadic, A., Compagnoni, L. \& Merloni, E. The impact of greenhouse gas emissions in the EU food chain: a quantitative and economic assessment using an environmentally extended input-output approach. J. Clean. Prod. 157, 168-176 (2017).

26. Boehm, R. et al. Life cycle assessment of greenhouse gas emissions from U.S. household food choices. Food Policy 79, 67-76 (2018).

27. Heller, M. C. \& Keoleian, G. A. Greenhouse gas emission estimates of U.S. dietary choices and food loss. J. Ind. Ecol. 19, 391-401 (2015).

28. Tichenor-Blackstone, N., El-Abbadi, N. G., McCabe, M. S., Griffin, T. S. \& Nelson, M. Linking sustainability to the healthy eating patterns of the dietary guidelines for Americans: a modelling study. Lancet Planet. Health 2, 3344-3352 (2018).

29. Tom, M. S., Fischbeck, P. S. \& Hendrickson, C. T. Energy use, blue water footprint, and greenhouse gas emissions for current food consumption patterns and dietary recommendations in the U.S. Environ. Syst. Decis. 36, 92-103 (2016)

30. IPCC Special Report on Climate Change, Desertification, Land Degradation, Sustainable Land Management, Food Security, and Greenhouse Gas Fluxes in Terrestrial Ecosystems (eds Shukler, P. R. et al.) (Imperial College, 2019).

31. National Academies of Sciences, Engineering, and Medicine Sustainable Diets, Food, and Nutrition: Proceedings of a Workshop-in Brief (National Academies Press, 2019)

32. Tilman, D. \& Clark, M. Global diets link environmental sustainability and human health. Nature 515, 518-522 (2014).

33. Data Products (U.S. Department of Agriculture Economic Research Service, 2019); https://www.ers.usda.gov/data-products/

34. Inter-Industry Relationships (Input/Output, Final Demand Matrix) (U.S. Bureau of Labor Statistics, 2020); https://www.bls.gov/emp/data/ input-output-matrix.htm

35. Miller, R. E. \& Blair, P. E. Input-Output Analysis: Foundations and Extensions 2nd edn (Cambridge Univ. Press, 2009).

36. FAOSTAT (Food and Agriculture Organization of the United Nations, 2019); http://www.fao.org/faostat/en/\#home

\section{Acknowledgements}

E.-M.M. acknowledges support from the German Research Foundation (DFG-fellowship GZ: ME 5179/1-1). The findings and conclusions in this manuscript are those of the authors and should not be construed to represent any official US Department of Agriculture or US government determination or policy. This work was supported by the Cornell SC Johnson College of Business and Cooperative Agreement number 58 4000-8-0051 between Cornell University and the Economic Research Service of the US Department of Agriculture.

\section{Author contributions}

Conceptualization: C.B.B., P.C. and M.I.G.; methodology: C.B.B., P.C., M.I.G. and E.-M.M.; software code development: P.C., E.K., J.L., V.M.-A., E.-M.M. and J.Y.; statistical analysis: P.C., E.K., J.L., V.M.-A., E.-M.M. and J.Y.; data curation: P.C. and J.Y.; writing of original draft: C.B.B.; review and editing: C.B.B., P.C., M.I.G., E.K., J.L., V.M.-A., E.-M.M and J.Y.; visualization: E.K. and J.Y.; supervision and project administration: C.B.B. and M.I.G.; funding acquisition: C.B.B. and M.I.G. The authors are listed in reverse alphabetical order in the author list but share seniority equally.

\section{Competing interests}

The authors declare no competing interests.

\section{Additional information}

Supplementary information The online version contains supplementary material available at https://doi.org/10.1038/s43016-021-00279-9.

Correspondence and requests for materials should be addressed to C.B.B.

Peer review information Nature Food thanks Rob Vos, Laurian Unnevehr, Andrea Cattaneo and the other, anonymous, reviewer(s) for their contribution to the peer review of this work.

Reprints and permissions information is available at www.nature.com/reprints. Publisher's note Springer Nature remains neutral with regard to jurisdictional claims in published maps and institutional affiliations.

(C) The Author(s), under exclusive licence to Springer Nature Limited 2021 


\section{Reporting Summary}

Nature Research wishes to improve the reproducibility of the work that we publish. This form provides structure for consistency and transparency in reporting. For further information on Nature Research policies, see our Editorial Policies and the Editorial Policy Checklist.

\section{Statistics}

For all statistical analyses, confirm that the following items are present in the figure legend, table legend, main text, or Methods section.

n/a Confirmed

Х $\square$ The exact sample size $(n)$ for each experimental group/condition, given as a discrete number and unit of measurement

Х $\square$ A statement on whether measurements were taken from distinct samples or whether the same sample was measured repeatedly

$\triangle$ The statistical test(s) used AND whether they are one- or two-sided

Х $\square$ Only common tests should be described solely by name; describe more complex techniques in the Methods section.

Х $\square$ A description of all covariates tested

$\square$ \ A description of any assumptions or corrections, such as tests of normality and adjustment for multiple comparisons

$\square$ A full description of the statistical parameters including central tendency (e.g. means) or other basic estimates (e.g. regression coefficient)

$\triangle$ AND variation (e.g. standard deviation) or associated estimates of uncertainty (e.g. confidence intervals)

$\square$ For null hypothesis testing, the test statistic (e.g. $F, t, r$ ) with confidence intervals, effect sizes, degrees of freedom and $P$ value noted

Give $P$ values as exact values whenever suitable.

Х $\square$ For Bayesian analysis, information on the choice of priors and Markov chain Monte Carlo settings

Х $\square$ For hierarchical and complex designs, identification of the appropriate level for tests and full reporting of outcomes

Х $\square$ Estimates of effect sizes (e.g. Cohen's $d$, Pearson's $r$ ), indicating how they were calculated

Our web collection on statistics for biologists contains articles on many of the points above.

\section{Software and code}

Policy information about availability of computer code

Data collection Data are compiled from Revision 4 of the Organisation for Economic Co-operation and Development (OECD) harmonized national inputoutput and use tables over a period of 11 years (2005 - 15) for 61 middle- and high-income countries.

Data analysis We adapt and scale the USDA's ERS food dollar series method globally.

For manuscripts utilizing custom algorithms or software that are central to the research but not yet described in published literature, software must be made available to editors and reviewers. We strongly encourage code deposition in a community repository (e.g. GitHub). See the Nature Research guidelines for submitting code \& software for further information.

\section{Data}

Policy information about availability of data

All manuscripts must include a data availability statement. This statement should provide the following information, where applicable:

- Accession codes, unique identifiers, or web links for publicly available datasets

- A list of figures that have associated raw data

- A description of any restrictions on data availability

The datasets and codes analysed and generated during the current study are available in the GitHub GlobalFoodDollar repository, [https://fedscornell.github.io/ GlobalFoodDollar/]. Source data for figures are provided with the paper. 


\section{Field-specific reporting}

Please select the one below that is the best fit for your research. If you are not sure, read the appropriate sections before making your selection.
Life sciences
Behavioural \& social sciences
Ecological, evolutionary \& environmental sciences

For a reference copy of the document with all sections, see nature.com/documents/nr-reporting-summary-flat.pdf

\section{Behavioural \& social sciences study design}

All studies must disclose on these points even when the disclosure is negative.

Study description

Research sample

Sampling strategy

Data collection

Timing

Data exclusions

Non-participation

Randomization
This study uses time-series quantitative data.

Data are compiled from Revision 4 of the Organisation for Economic Co-operation and Development (OECD) harmonized national input-output and use tables over a period of 11 years (2005 - 15) for 61 middle- and high-income countries.

Data are constructed based on all avaiable countries from the OECD tables.

Data are compiled from OECD public data.

$2005-15$

Ireland, Luxemburg, and Turkey are excluded from the study becuase data for Ireland show extremely high purchaser price mark-ups. Luxemburg and Turkey present extremly low and high farm shares, respectively.

$\mathrm{n} / \mathrm{a}$

$\mathrm{n} / \mathrm{a}$

\section{Reporting for specific materials, systems and methods}

We require information from authors about some types of materials, experimental systems and methods used in many studies. Here, indicate whether each material, system or method listed is relevant to your study. If you are not sure if a list item applies to your research, read the appropriate section before selecting a response.

\begin{tabular}{|c|c|}
\hline$n / a$ & Involved in the study \\
\hline$\bigotimes$ & Antibodies \\
\hline$凶$ & Eukaryotic cell lines \\
\hline 邓 & Palaeontology and archaeology \\
\hline$凶$ & Animals and other organisms \\
\hline$\bigotimes$ & Human research participants \\
\hline$\bigotimes$ & $\square$ Clinical data \\
\hline$\bigotimes$ & $\square$ Dual use research of concern \\
\hline
\end{tabular}

\begin{tabular}{l|l}
\multicolumn{2}{l}{ Methods } \\
\hline n/a & Involved in the study \\
$\square$ & $\square$ ChIP-seq \\
$\square$ & $\square$ Flow cytometry \\
$\square$ & $\square$ MRI-based neuroimaging
\end{tabular}

